Proceedings of the 2011 Winter Simulation Conference

S. Jain, R.R. Creasey, J. Himmelspach, K.P. White, and M. Fu, eds.

\title{
A DECISION FRAMEWORK FOR ENERGY USE REDUCTION INITIATIVES IN COMMERCIAL BUILDINGS
}

\author{
Elie Azar \\ University of Wisconsin-Madison \\ Department of Civil and Environmental \\ Engineering \\ 2231 Engineering Hall 1415 Engineering Drive \\ Madison, WI 53706, USA
}

\author{
Carol C. Menassa \\ University of Wisconsin-Madison \\ Department of Civil and Environmental \\ Engineering \\ 2318 Engineering Hall 1415 Engineering Drive \\ Madison, WI 53706, USA
}

\begin{abstract}
Energy consumption in commercial buildings and the resulting production of green house gas emissions continues to be one of the major challenges facing the United States. With more than 80 percent of the energy consumed by buildings occurring during their operational phase, most policies and programs over the last decade have focused on the design requirements for new and renovated buildings to ensure reductions in energy use during building operation. These policies are primarily focusing on the technical aspect of building systems, ignoring the role played by occupants' behavior, and most importantly how to influence this behavior to reduce energy consumption. Various approaches have proven to be effective in inducing behavioral changes such as energy conservation campaigns, financial incentives, feedback techniques, and others. This paper presents an agent-based approach to modeling these methods, simulating their impact on occupants' behavior, and predicting their effect on building energy use and costs.
\end{abstract}

\section{INTRODUCTION}

The building sector accounts for 30 to 40 percent of global energy use and can play a key role in mitigating the impact and risks of global warming (UNEP 2007). More than 80 percent of the energy consumed in buildings occur during their operating phase. Therefore, governments have been utilizing a variety of policies and instruments to support energy reduction during building operation as an immediate and costeffective way to reduce greenhouse gas emissions (Carrico and Riemer 2011, Allcott and Mullainathan 2010, UNEP 2007).

In the United States (US), commercial buildings in particular present an important opportunity for energy savings. Every year, nearly 5 million commercial buildings consume 19 percent of the total national energy use, emit more than one billion metric tons of carbon dioxide, and result in $\$ 95$ billion in energy costs (US EIA 2003). These facts highlight the economic and environmental impact of potential energy reductions in the commercial building sector.

Two different approaches can typically be used to reduce buildings' energy use. First, the technological approach consists of investing in more energy efficient building systems and equipment. Second, the behavioral approach focuses on encouraging building occupants to adopt energy saving practices (Carrico and Riemer 2011; Dietz et al. 2009; Henryson, Hakansson, and Pyrko 2000). US policies and programs over the past decade have solely focused on energy reduction through technology, overlooking the significant potential energy savings from occupancy behavioral changes (ARRA 2009, EPA 2005). The main focus on the 'technological' rather than 'behavioral' energy use solutions is in part due to the higher level of predictability associated with technology related investments (Carrico and Riemer 2011; Henryson, Hakansson, and Pyrko 2000). For instance, one would argue that it is easier to predict building energy 
savings resulting from replacing incandescent light bulbs with fluorescent ones, rather than trying to influence occupants' energy consumption characteristics.

However, literature has proven that several behavioral energy conservation techniques are effective and result in significant energy and monetary savings (Peschiera, Taylor, and Siegel 2010; Jackson 2005; Staats, Harland, and Wilke 2004; Staats, van Leeuwen, and Wit 2000). The most commonly used tools are energy informational feedback, energy social marketing campaigns, and financial incentives. Stakeholders (e.g., building owners) can directly benefit from these tools to reach their energy savings goals. However, in order to optimize the choice of methods, they must be well-informed and able to predict and simulate the impact of these energy conservation interventions on their specific buildings (CRS 2009; Henryson, Hakansson, and Pyrko 2000).

\section{OBJECTIVES}

The aim of this paper is to present a new framework that models the impact of different energy conservation interventions on building energy use and associated energy costs. The considered life-cycle approach to energy consumption in buildings allows for fair and comprehensive comparisons between various energy conservation alternatives. So, the main outcome of this research is a computational model that (1) predicts the initial building energy use, (2) simulates the impact of energy conservation interventions on the building occupants' energy use, (3) calculates the changing energy consumption levels, and (4) calculates the life-cycle energy costs paid by the building owner, which include energy bills and the implementation costs of the energy conservation interventions.

\section{BACKGROUND}

The first step in this research was to perform an extensive literature review to evaluate and understand: (1) the impact of occupants on energy use, (2) the different factors that might cause occupants energy behavioral changes, and (3) the different energy modeling techniques typically used to predict building energy use.

\subsection{Impact of Occupants on Building Energy Use}

Several studies have proven that building energy consumption is highly dependent on occupants' energy use behavior, and that significant energy savings can be obtained if this behavior was modified (Yudelson 2010, Dell'lsola and Kirk 2003, Soebarto and Williamson 2001). In commercial buildings, more energy is often used during non-working hours (56 percent) than during working hours (44 percent) mainly due to occupancy related actions (Masoso and Groblera 2009). For instance, Sanchez et al. (2007) and Webber et al. (2006) showed that less than 50 percent of office building equipment is switched off by building occupants during non-operating hours, resulting in unnecessary energy use. Another study by Bourgeois, Reinhart, and Macdonald (2006) considered light switching patterns of occupants and the resulting impact on building energy use. Results from this study showed that occupants that actively seek day lighting consume 40 percent less energy when compared to occupants who constantly rely on artificial lighting. All of these studies highlight the significant energy savings potential in commercial buildings, and the motivation to change energy use behavior among occupants. To address these occupancy related issues, several energy conservation interventions are available in literature and have proven to result in building energy savings.

\subsection{Energy Conservation Interventions}

The most common and effective energy conservation interventions typically used in commercial buildings are: (1) feedback, (2) occupants energy education, and (3) energy social marketing campaigns.

First, feedback techniques are believed to be among the most consistent and efficient energy conservation interventions. Many studies in literature show that sharing energy consumption information of a 
building with its occupants can lead to significant energy savings. This is particularly important in commercial buildings, where there are typically no financial incentives for occupants to save energy (Carrico and Reimer 2011; Faruqui, Sergici, and Sharif 2010; Peschiera, Taylor, and Siegel 2010; Staats, Harland, and Wilke 2004). Faruqui, Sergici, and Sharif (2010) evaluated the impact of this technique by gathering information about 12 feedback pilot programs that were conducted on residential buildings in North America and abroad. Energy savings from these programs ranged from 3 to 13 percent, with an average of 7 percent. Carrico and Reimer (2011) tested feedback on 24 office-type commercial buildings, also leading to an average of 7 percent in energy savings.

Second, occupants energy education consists of increasing building occupants' knowledge of environmental problems and of energy saving practices they can adopt to reduce their impact on the environment. It is assumed that more knowledge will result in changes in attitudes, which in turn affects behavior. Educating occupants is typically achieved through energy conservation trainings/workshops, or through specific occupants that are assigned to promote energy conservation (Steg and Vlek 2009; Abrahamse et al. 2005; Lehman and Geller 2004). This technique is on average less effective than other methods such as feedback, which was confirmed by Carrico and Reimer (2011) who observed an efficiency of only 4 percent in office-type commercial buildings.

Third, social marketing is "the use of marketing principles and techniques to influence a target audience to voluntarily accept, reject, modify, or abandon a behavior for the benefit of individuals, groups, or society as a whole" (Kotler, Roberto, and Lee 2002). In this research, energy social marketing represents social marketing campaigns that promote good energy consumption practices to reduce building energy consumption. Many social marketing programs that are found in literature resulted in important energy savings. These programs typically applied the McKenzie-Mohr's principles of Community-Based Social Marketing (McKenzie-Mohr 2000). The best known and documented example is the Ecoteams program established internationally as part of the Global Action Plan for the Earth to reduce household resource consumption. This program successfully induced a reduction of 9 to 17 percent for domestic energy consumption in the US cities studied (Pickens 2002).

It is also possible that occupants change behavior and adopt in some cases bad energy consumption habits, due to the often called 'rebound effect' (Sorrell, Dimitropoulos, and Sommerville 2009). For instance, occupants might tend to use more electric lighting following the installation of energy saving bulbs, assuming that their actions have less impact on the environment.

After studying the impact of occupants' behavior on building energy use and evaluating different behavioral changing techniques, the next step was to review the most common tools that model energy consumption in building.

\subsection{Energy Modeling Techniques and Tools}

A number of empirical and simulation models exist and are widely used during the design phase of buildings to predict their energy consumption during operation. The most common software programs are $E n$ ergyPlus, eQuest, and Energy-10 (SBCI 2010, EnergyPlus 2009, eQuest 2009). However, these software provide very little flexibility when accounting for occupants, ignoring the impact of their behavior on building energy use. They assume that all building occupants have the same energy consumption behavior, and that occupants energy use characteristics are constant over time (Hoes et al. 2009; Turner and Frankel 2008). This is believed to be the main limitation of traditional energy modeling software, resulting in large discrepancies (exceeding 30 percent) between their generated energy predictions and actual energy consumption levels (Yudelson 2010, Dell'lsola and Kirk 2003, Soebarto and Williamson 2001). As a result, these software programs cannot be used to evaluate energy conservation interventions. Therefore, a new type of energy modeling tools is needed that is capable of modeling occupants in a dynamic way, accounting for different energy consumption patterns, and allowing for changes in occupants' energy use characteristics over time. 


\section{METHODOLOGY}

Three main steps were required to achieve this study's objectives: (1) study different simulation techniques and choose the most appropriate one to model occupants behavior, (2) determine different levels of energy consumption in buildings, and (3) build a computational model to predict energy use and simulate the impact of energy conservation interventions on building energy use and cost.

\subsection{Choose a Simulation Technique/Software}

Three main simulation techniques were identified in literature that are capable of modeling the social behavioral aspects of occupants: Discrete Events (DE), System Dynamics (SD), and Agent-Based Modeling (ABM). While DE and SD are considered to a certain extent as centralized structures requiring the user to define the global system behavior (systems), ABM is decentralized where the modeler defines behavior at an individual level. In this 'bottom-up' modeling method, the global behavior emerges as a result of many individuals (each following its own behavior rules) interacting with each other and with their environment (Gilbert 2008; Edmonds, Hernández, and Troitzsch 2007; Borshchev and Filippov 2004). More specifically, agent-based models consist of individual agents, commonly implemented in software as objects. Agent objects have states and rules of behavior. Running such models simply amounts to instantiating an agent population, letting the agents interact, and monitoring what happens (Axtell 2000). These simulation characteristics led to the choice of ABM as the simulation framework for this research, where building occupants can be modeled as agents with specific attributes (e.g., energy consumption behaviors) who might be subjected to energy conservation interventions that change their attributes over time (e.g., reduce energy consumption).

The Agent-Based Modeling platform that was chosen for this research is the widely used simulation software Anylogic (XJ Technologies 2009; Borshchev and Filippov 2004). The choice of Anylogic was mainly due to its Java-based environment that allows the user to develop custom Java codes, and integrate them in pre-built simulation blocks (XJ Technologies 2009). This was essential in this research to optimize and customize the proposed model in order to simulate the complex behavioral aspects of building occupants. Before building the model, it was necessary to determine different energy consumption levels of building occupants. This is key to translating the change in behavior of occupants due to energy conservation interventions to a change in building energy use.

\subsection{Determine Levels of Energy Use}

The goal of this section is to determine different occupants' energy use patterns to represent the different and changing occupants' energy characteristics over time. Therefore, three different types of occupants energy behavior were considered: Medium Energy Consumers (MEC), High Energy Consumers (HEC), and Low Energy Consumers (LEC). First, MEC represent building occupants that consume energy at normal rates without being influenced by factors that induce decreases (e.g., feedback, energy conservation education), or increases in energy use (e.g., rebound effect). Second, LEC represent occupants that were successfully influenced to reduce their energy consumption, or occupants that initially are energy efficient and do not need incentives to adopt energy saving practices. Finally, HEC represent the other extreme with occupants that over consume energy. These assumptions were made based on a study by Accenture (2010) that classified energy consumers in different countries around the world into eight different categories based on their attitude toward energy management programs. However, after discussions with industry professionals, it was assumed in this paper that three categories of occupants are adequate to observe differences in energy consumption levels. These categories also help understand the maximum and minimum energy consumption levels that a building under study could reach. For instance, to represent a typical building with average energy consumption rates, all of its occupants can be assumed MEC. Then, by applying energy conservation techniques, some of the building occupants might change behavior and become LEC. This could lead to a drop in energy consumption, reaching a minimum when all of the occupants become LEC. 
Ideally, the energy use rates for the three categories of occupants should be determined on a case by case basis, depending on building characteristics, weather conditions, building operations, etc. However, national buildings energy use averages were used in this study to estimate the rates of energy use for MEC, HEC, and LEC. These rates are summarized in Table 1, which was adapted from '2003 Commercial Buildings Energy Consumption Survey' of the US Energy Information Administration (US EIA 2003). This portion of the survey was based on data collected from 4,859 office buildings, resulting in statistical significance for the numbers presented in Table 1. The 'Median' values were first assumed to represent MEC, who typically have an average (non-extreme) energy consumption behavior. The ' $25^{\text {th }}$ percentile' values represent the lower segment of the collected energy data, and were therefore associated with LEC. Finally, the ' $75^{\text {th }}$ percentile' represent high energy use rates, and were assigned to HEC.

Table1: Energy consumption rates

\begin{tabular}{|l|c|c|c|c|c|c|}
\hline \multirow{2}{*}{$\begin{array}{l}\text { Type of Office } \\
\text { Building }\end{array}$} & \multicolumn{3}{|c|}{$\begin{array}{c}\text { Annual Electric Consumption } \\
\text { [kWh / person] }\end{array}$} & \multicolumn{3}{c|}{$\begin{array}{c}\text { Annual Gas Consumption } \\
\text { [Btu / person] }\end{array}$} \\
\cline { 2 - 7 } & $\begin{array}{c}\text { 25th } \\
\text { Percentile }\end{array}$ & Median & $\begin{array}{c}\text { 75th } \\
\text { Percentile }\end{array}$ & $\begin{array}{c}\text { 25th } \\
\text { Percentile }\end{array}$ & Median & $\begin{array}{c}\text { 75th } \\
\text { Percentile }\end{array}$ \\
\cline { 2 - 7 } & LEC & MEC & HEC & LEC & MEC & HEC \\
\hline $\begin{array}{l}\text { Administrative / } \\
\text { Professional }\end{array}$ & $2,901.1$ & $4,763.0$ & $6,495.0$ & $8,093,376.2$ & $15,830,999.6$ & $26,147,830.8$ \\
\hline Bank/Financial & $6,873.0$ & $10,522.8$ & $13,983.0$ & $6,961,211.4$ & $11,537,112.6$ & $27,358,047.6$ \\
\hline Government & $3,102.3$ & $4,098.1$ & $7,391.9$ & $9,007,508.9$ & $14,946,958.0$ & $20,335,729.7$ \\
\hline Other Office & $2,067.8$ & $4,262.2$ & $6,541.0$ & $6,544,249.4$ & $14,605,377.8$ & $24,226,724.6$ \\
\hline
\end{tabular}

\subsection{Build a Computational Simulation Model}

The next step was to build an agent-based model that allows the user to model a certain office building, schedule energy conservation interventions that the building occupants will be subjected to, and finally predict and quantify the impact of these interventions on building energy use while calculating the associated monetary costs. In this section, the model inputs are first presented, followed by the model's flowchart or the simulation engine, and finally the model outputs showing the type of information generated by the proposed model.

\subsubsection{Model Inputs}

Three levels of inputs are required by the user to run the proposed agent-based model. The first level is the building/occupants level where the user is required to specify the type of office building under study (e.g., Administrative, bank/financial, government ,etc.), and enter the average number of people occupying the building. By default, it is assumed that the building occupants are initially MEC, showing no extreme (high or low) energy consumption patterns. However, depending on the level of information available about the occupants, the user can specify their specific energy consumption characteristics by determining how many of them are MEC, HEC, and LEC. It is important to note that these numbers can change throughout the simulation due to energy conservation interventions as discussed later. These building/occupants related inputs, in addition to the energy use rates of Table 1, are used to calculate the average, the maximum, and the minimum energy consumption levels of the building under study.

The second level of inputs is used for the energy cost calculation. At this stage, the user is required to enter the cost per energy unit of electricity and gas, in addition to the 'opportunity rate of return' which is 
the discount rate that could be earned from some alternative investment opportunity (Dell'Isola and Kirk 2003).

The third and final level of inputs is related to the type, frequency, effectiveness, and cost of energy conservation interventions. This is where the user can schedule events that typically induce changes in occupants energy use behavior. More specifically, four types of energy behavior changing techniques can be modeled: (1) Feedback, (2) Occupants energy education, (3) Energy social marketing campaigns, (4) Rebound effect. While the first three methods typically induce reductions in energy consumption, the rebound effect represents a possible counter-reaction of occupants with an increase in energy use (Refer to the 'Background' section for more details).

In the developed model, default values were set for all of the above-mentioned parameters to help the user run the model without necessarily knowing the values of all the required inputs. So, the user can customize the model by specifying his/her own parameters, or use the default suggested values. These values result from the extensive literature review that was performed for this study to gather information from national energy databases in addition to academic works/research. For instance, the default prices of electricity and gas that were used are $\$ 0.1011 / \mathrm{kWh}$ and $\$ 6.04 / 10^{\wedge} 6 \mathrm{Btu}$, which were obtained from the Power Monthly Report of the US Energy Information Administration (US EIA 2011). Another example is the effectiveness of feedback interventions techniques, which was obtained from the studies of Carrico and Reimer (2011) and Faruqui, Sergici, and Sharif (2010) that both observed an average reduction in energy use by 7 percent when applying these feedback methods.

\subsubsection{Model's Flowchart}

The model flowchart is shown in Figure 1 where a four-step iterative process was defined to ultimately generate energy consumption estimates and associated costs. In step 1, the energy consumption rates for MEC, HEC, and LEC that were shown in Table 1 are imported into the model to be used at later stages. In step 2, the model checks if an energy conservation intervention was scheduled by the user for this specific time step such as feedback, occupants energy education, or energy social marketing campaigns. In that case, the model calculates the changes in occupants' behavior expressed by the conversion of occupants towards less energy consuming categories. More specially, a portion of HEC become MEC, and a portion of MEC become LEC. It is important to note that the actual number of occupants changing behavior depends on the efficiency of the specific energy conservation intervention occurring. This parameter is specified by the user before the start of the simulation as was discussed in the previous section. At the end of Step 2, the model updates the number of MEC, LEC, and HEC in the building under study. In step 3, the model checks if a rebound effect is occurring at this time step, leading to an change in behavior and an increase in energy consumption. In this case, the conversion of occupants occurs towards the high energy consumption categories, where some LEC become MEC and some MEC convert to HEC. Here again, the occurrence time and the impact of the rebound effect is previously specified by the user. In step 4, the model combines the updated number of MEC, LEC, and HEC and applies the energy use rates that were entered in Step 1 in order to calculate and plot the total building energy use for this time step. Then, the model generates the corresponding energy costs using the financial-related inputs that were entered by the user (Refer to section 3.3.1 for more details). Finally, the model moves to the next time-step by going back to Step 2, and keeps repeating this cycle until the total simulation time is reached.

\subsubsection{Model's Outputs}

A case study example was used in this section to illustrate the proposed model's capabilities. The building that was modeled is a 5-story 647,000 sq. ft. (approximately 60,000 sq. m.) commercial office building located in Pittsburgh, PA, and accommodating on average 1,800 occupants. These building characteristics were obtained from the US DOE's 'Buildings Database' (US DOE 2011). 


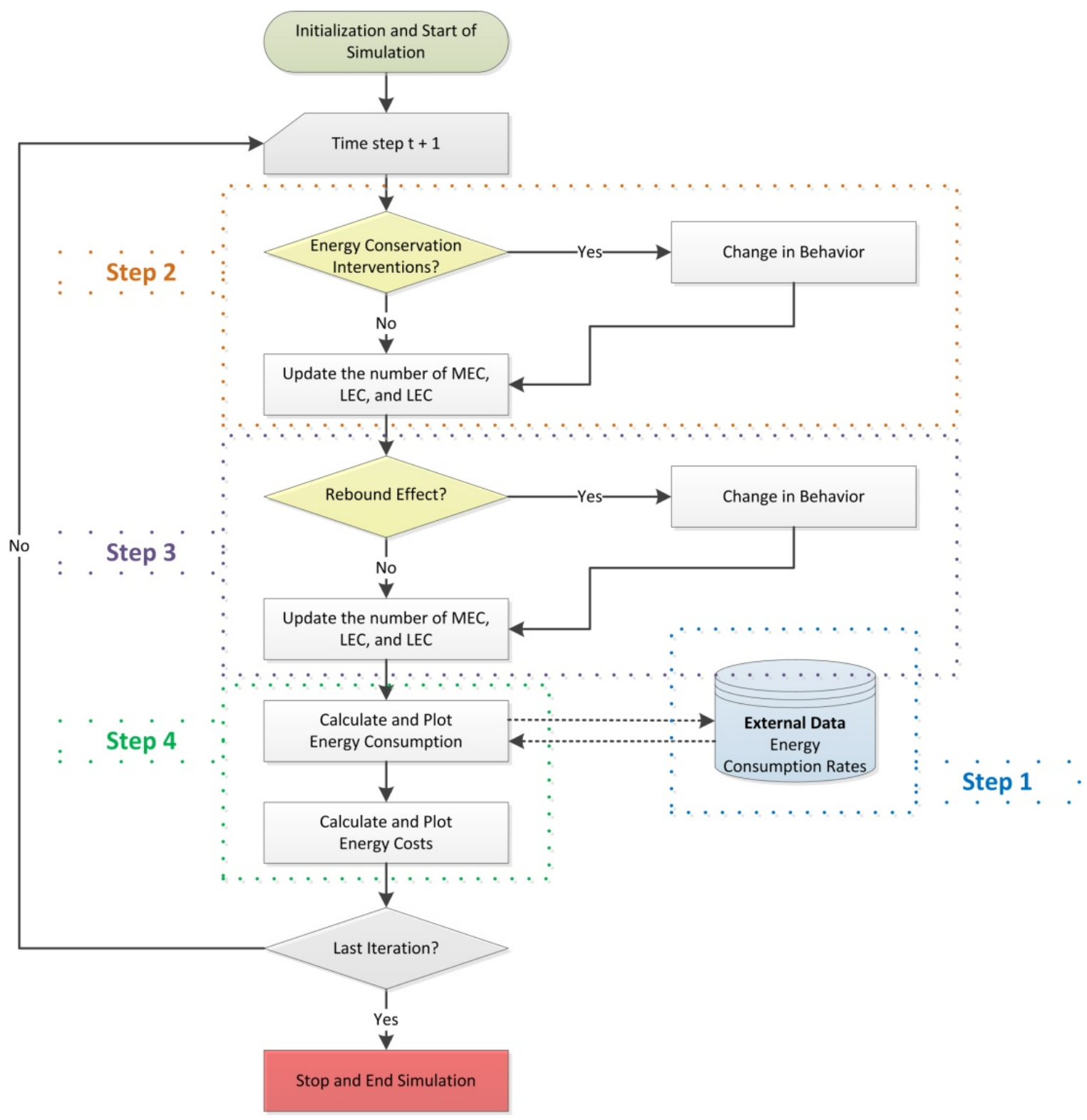

Figure 1: Proposed model flowchart

In this example, two energy behavioral changing events were scheduled to show how the model simulates the potential changes in occupants behavior and the resulting impacts on energy use and cost. More specifically, one 'Feedback' event was scheduled at month 12, which is expected to reduce energy consumption, and one 'Rebound Effect' was scheduled at month 24 showing the opposite case of potential increases in energy use. So, the first intervention occurs at month 12 and involves installing energy feedback tools to inform occupants about their energy consumption levels (e.g., big screen with real-time energy use data). The capital cost of installing these tools was estimated at $\$ 40,000$ for this example, and the effectiveness of the 'Feedback' and the 'Rebound effects' at 7 percent and 4 percent respectively (Refer to section 3.3.1 for more details about the model inputs). It was also assumed in this example that building occupants are initially MEC, reflecting average energy consumption rates. However, once subjected to the above-mentioned events, some of these occupants are expected to change behavior and convert to the LEC or HEC categories. The total simulation time for this example was 36 months. 


\section{Azar and Menassa}

Figure 2 shows the proposed model output interface with four different graphs. Graph A illustrates the number of MEC, HEC, and LEC over time, representing the energy consumption behavior of the building occupants. Graph B plots the total monthly energy consumption level for the building. Graph C shows the estimated costs paid by the building owners including the energy costs in addition to the capital cost of implementing the 'Feedback' tools. Finally, as shown in Graph D, these monthly costs are discounted to the present time (2011) to show the net present value of the total costs in 2011 equivalent dollars. Two key moments can be identified in Figure 2 where occupants' behaviors have changed. These variations were specifically triggered by the two energy conservation events scheduled for months 12 and 24.

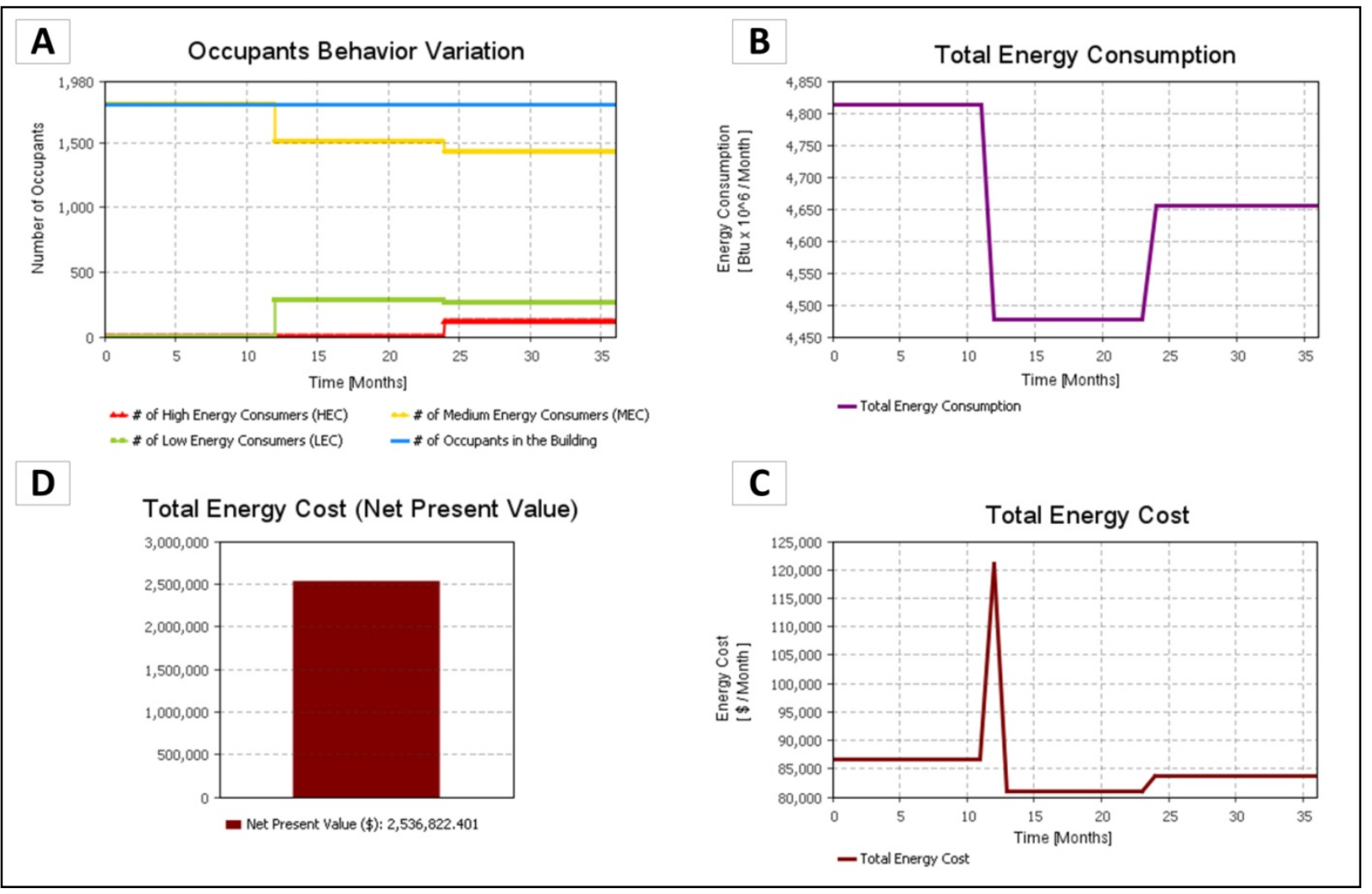

Figure 2: Proposed Model Output

First, the 'Feedback' event at month 12 caused the conversion of some MEC to LEC (Refer to Graph A of Figure 2). This change in behavior resulted in a drop in the total energy consumption by 7 percent as shown in Graph B. The initial cost of $\$ 40,000$ associated with the 'Feedback' implementation caused a sudden increase in the total costs at month 12 , followed by the decrease in monthly costs due to the reduction in energy use (Refer to Graph C).

Second, the 'Rebound Effect' that was scheduled at month 24 caused in this case an increase in the number of HEC (Graph A). This change in behavior provoked an increase of 4 percent in the building energy consumption (Graph B), and a corresponding increase in the monthly and total energy costs paid by the building owner (Graphs $\mathrm{C}$ and $\mathrm{D}$ respectively).

\subsubsection{Sensitivity Analysis}

This section shows an example of the sensitivity analyses that were performed to test the model's reaction to changes in input parameters. In accordance with the study's objectives, a specific emphasis was put on 
the role of occupants by varying parameters related to their behavior and interactions, and ultimately tracking the resulting changes in energy use and costs. The analysis was performed on the same building used in the previous section, with one base case and four different scenarios considered. A summary of the input parameters that were varied for this analysis in addition to the output results can be found in Table 2. First, the base case represents the case with no energy behavioral changing methods. Therefore, all of the occupants in this case were assumed to remain MEC throughout the simulation time. Scenario 1 has a 'Feedback' conservation intervention scheduled at month 12. The second scenario is similar to the first one but with a capital cost of $\$ 40,000$ for the 'Feedback' intervention. Scenarios 3 and 4 have an additional 'Rebound Effect' scheduled from month 24, with respective effectiveness of 2 and 5 percent.

Table 2: Sensitivity Analysis

\begin{tabular}{|l|c|c|c|c|c|}
\hline Input Parameters & Base Case & Scenario 1 & Scenario 2 & Scenario 3 & Scenario 4 \\
\hline 'Feedback' Occurrence & None & Month 12 & Month 12 & Month 12 & Month 12 \\
\hline 'Feedback' Effectiveness & None & 7 percent & 7 percent & 7 percent & 7 percent \\
\hline 'Feedback' Initial Cost & None & $\$ 0$ & $\$ 40,000$ & $\$ 40,000$ & $\$ 40,000$ \\
\hline 'Rebound Effect' Occurrence & None & None & None & Month 24 & Month 24 \\
\hline 'Rebound Effect' Effectiveness & None & None & None & 2 percent & 5 percent \\
\hline \hline Output Results & Base Case & Scenario 1 & Scenario 2 & Scenario 3 & Scenario 4 \\
\hline $\begin{array}{l}\text { Total Energy Consumption } \\
(36 \text { months) [Btu x 10^6] }\end{array}$ & 173,245 & 165,185 & 165,185 & 166,247 & 167,863 \\
\hline $\begin{array}{l}\text { Net Present Value Cost } \\
\text { [\$ x 10^3] }\end{array}$ & 2,585 & 2,478 & 2,512 & 2,524 & 2,543 \\
\hline
\end{tabular}

As expected, the addition of a 'Feedback' intervention for scenarios 1 and 2 resulted in a drop in energy consumption from the base case. Energy consumption increased in scenarios 3 and reached a maximum in scenario 4 when 'Rebound Effects' were added with 2 and 5 percent efficiencies respectively. Similarly for the net present value cost, the minimum value was observed in scenario 1 where a 'Feedback' intervention occurred with no initial implementation costs. This cost increased for scenario 2 where an implementation cost of $\$ 40,000$ was considered for the 'Feedback' intervention. The total cost kept increasing in Scenario 3 by adding a rebound effect with a 2 percent efficiency. Finally, the highest cost was observed in Scenario 4 where a 'Rebound' effectiveness was increased to 5 percent.

The results from Table 2 confirmed that the model is responding in a logical manner to changes in the above input parameters. This is just one example of the several sensitivity analyses that were performed to verify the model and validate its technical/computational performance. As part of future research, real data will be collected and used to improve the model, and ultimately validate its generated outputs.

\section{CONCLUSION}

In conclusion, reducing energy consumption in commercial buildings has become a major objective for the US government, as part of a national and global effort to reduce greenhouse gases emissions (ARRA 2009, UNEP 2007, EPA 2005). Most of the efforts that have been put so far to reach this goal have focused on 'technological' solutions, overlooking 'behavioral changing' options that have also proven to be effective (Carrico and Riemer 2011; Dietz et al. 2009; Henryson, Hakansson, and Pyrko 2000). These energy conservation interventions include, but are not limited to: Feedback techniques, energy social marketing campaigns, occupants energy education, and financial incentives (Peschiera, Taylor, and Siegel 2010; Jackson 2005; Staats, Harland, and Wilke 2004; Staats, van Leeuwen, and Wit 2000).

The aim of this research was to present a new framework to study and evaluate the impact of these energy conservation techniques on commercial buildings. To achieve this goal, a computational agent- 
based model was developed, which allows the user to model a certain commercial building environment, and test the impact of different energy conservation interventions on its energy use and associated costs. This life-cycle cost approach can mostly benefit decision-makers such as building owners or energy policy makers to make more informed decision about investing in different energy conservation methods, and ultimately reaching their energy saving goals.

The proposed agent-based model presents a good foundation for an eventual software program that can be disseminated for real-life applications. The model has so far been verified but still needs validation to ensure an accurate and reliable representation of the buildings under study. Future research also includes expanding the model to include more types of commercial buildings, additional and more detailed energy conservation interventions, and finally more advanced economic evaluation methods.

\section{REFERENCES}

Abrahamse, W., L. Steg, C. Vlek, and T. Rothengatter. 2005. "A Review of Intervention Studies Aimed at Household Energy Conservation." J. Environ. Psychol. 25(3):273-291.

Accenture. 2010. "Understanding Consumer Preferences in Energy Efficiency." Accessed June 4, 2011. http://www.accenture.com/SiteCollectionDocuments/PDF/Understanding_Consumer_Preferences_En ergy_Efficiency_10-0229_Mar_11.pdf.

Allcott, H., and S. Mullainathan. 2010. "Behavior and energy policy." Science 327(5970):1204.

ARRA. 2009. "American Recovery and Reinvestment Act (ARRA) of 2009. Public Law 111-5." In U.S. Congressional Record, Vol. 155. Released Feb. 17, 2009.

Axtell, R. 2000. Why Agents?: on the Varied Motivations for Agent Computing in the Social Sciences. Center on Social and Economic Dynamics, Brookings Institution, Washington, DC.

Borshchev, A., and A. Filippov. 2004. "From System Dynamics and Discrete Event to Practical Agent Based Modeling: Reasons, Techniques, Tools." In Proceedings of $22^{\text {nd }}$ International Conference of the System Dynamics Society. Oxford, England.

Bourgeois, D., C. Reinhart, and I. Macdonald. 2006. "Adding Advanced Behavioural Models in Whole Building Energy Simulation: a Study on the Total Energy Impact of Manual and Automated Lighting Control." Energy Build. 38(7):814-823.

Carrico, A. R., and M. Riemer. 2010. "Motivating Energy Conservation in the Workplace: An Evaluation of the Use of Group-Level Feedback and Peer Education." J. Environ. Psychol. 31(1):1-13.

CRS (Congressional Research Service). 2009. "Energy efficiency in buildings: Critical Barriers and Congressional Policy.” Accessed June 2011. http://nepinstitute.org/get/CRS_Reports/CRS_Energy/Energy_Efficiency_and_Conservation/Energy_ Efficiency_in_Buildings.pdf.

Dell'Isola, A. J., and S. J. Kirk. 2003. "Life Cycle Costing for Facilities." Reed Construction Data, Kingston, MA.

Dietz, T., G. T. Gardner, J. Gilligan, P. C. Stern, and M. P. Vandenbergh. 2009. "Household Actions can Provide a Behavioral Wedge to Rapidly Reduce US Carbon Emissions." In Proceedings of the National Academy of Sciences 106(44):18452-18456.

Edmonds, B., C. Hernández, and K. G. Troitzsch. 2007. Social Simulation Technologies, Advances and New Discoveries. Hershey, PA: Information Science Reference.

EnergyPlus. 2009. "Input/Output Reference: The Encyclopedic Reference to EnergyPlus Input and Output." The Board of Trustees of the University of Illinois and the Regents of the University of California through the Ernest Orlando Lawrence Berkeley National Laboratory, Urbana, IL.

EPA (Energy Policy Act). 2005. "Public Law 109-58: 109th Congress An Act To Ensure Jobs for Our Future with Secure, Affordable, and Reliable Energy."

eQuest. 2009. "Introductory Tutorial, version 3.63." James J. Hirsh \& Associates, Camarillo, CA.

Faruqui, A., S. Sergici, and A. Sharif. 2010. "The Impact of Informational Feedback on Energy Consumption--A Survey of the Experimental Evidence." Energy 35(4):1598-1608. 
Gilbert, G. N. 2008. Agent-Based Models. London, United-Kingdom: Sage Publications, Inc,.

Henryson, J., T. Hakansson, and J. Pyrko. 2000. "Energy Efficiency in Buildings through InformationSwedish Perspective." Energy Policy 28(3):169-180.

Hoes, P., J. L. M. Hensen, M. Loomans, B. De Vries, and D. Bourgeois. 2009. "User Behavior in Whole Building Simulation." Energy Build. 41(3):295-302.

Jackson, T. 2005. "Motivating Sustainable Consumption: A Review of Evidence on Consumer Behaviour and Behavioural Change." Centre for Environmental Strategy, University of Surrey, Surrey, UnitedKingdom.

Kotler, P., N. Roberto, and N. Lee. 2002. Social marketing: Improving the Quality of Life. Thousand Oaks, CA: Sage Publications, Inc.

Lehman, P. K., and E. S. Geller. 2004. "Behavior Analysis and Environmental Protection: Accomplishments and Potential for More." Behavior and Social Issues 13(1):13-32.

MacKenzie-Mohr, D. 2000. "Promoting Sustainable Behaviour: An Introduction to Community-Based Social Marketing." J. Soc. Iss. 56(3):543-554.

Masoso, O. T., and L. J. Grobler. 2010. "The Dark Side of Occupants' Behaviour on Building Energy Use." Energy Build. 42(2):173-177.

Peschiera, G., J. E. Taylor, and J. A. Siegel. 2010. "Response-Relapse Patterns of Building Occupant Electricity Consumption following Exposure to Personal, Contextualized and Occupant Peer Network Utilization Data." Energy Build. 42(8):1329-1336.

Pickens, P. M. 2002. "Community-Based Social Marketing as a Planning Tool: Community and Regional Planning Masters Project." University of Oregon-Architecture and Allied Arts Department, Eugene, OR.

Sanchez, M., C. Webber, R. Brown, J. Busch, M. Pinckard, and J. Roberson. 2006. "Space Heaters, Computers, Cell Phone Chargers: How Plugged In are Commercial Buildings?" In 2006 ACEEE Summer Study on Energy Efficiency in Buildings, Less is More, En Route to Zero Energy Buildings, .

SBCI (Sustainable Building Industry Council). 2008. "Energy-10® Software." Accessed June 4, 2011. http://www.sbicouncil.org/energy-10-software.

Soebarto, V. I., and T. J. Williamson. 2001. "Multi-Criteria Assessment of Building Performance: Theory and Implementation." Build. Environ. 36(6):681-690.

Sorrell, S., J. Dimitropoulos, and M. Sommerville. 2009. "Empirical Estimates of the Direct Rebound Effect: A Review." Energy Policy 37(4):1356-1371.

Staats, H., P. Harland, and H. A. M. Wilke. 2004. "Effecting Durable Change: A Team Approach to Improve Environmental Behavior in the Household." Environ. Behav. 36(3):341-367.

Staats, H., E. van Leeuwen, and A. Wit. 2000. "A Longitudinal Study of Informational Interventions to Save Energy in an Office Building." J. Appl. Behav. Anal. 33(1):101-104.

Steg, L., and C. Vlek. 2009. "Encouraging Pro-Environmental Behaviour: An Integrative Review and Research Agenda." J. Environ. Psychol. 29(3):309-317.

Turner, C., and M. Frankel. 2008. "Energy Performance of LEED for New Construction Buildings." Accessed June 4, 2011. http://www.usgbc.org/ShowFile.aspx?DocumentID=3930.

US DOE (Department of Energy). 2011. "Buildings Data Base". Accessed June 5, 2011. http://eere.buildinggreen.com/overview.cfm?projectid=62.

US EIA (Energy Information Administration). 2003. "2003 Commercial Buildings Energy Consumption Survey." Accessed June 4, 2011. http://www.eia.gov/emeu/cbecs/contents.html.

US EIA (Energy Information Administration). 2011. "Electric Power Monthly Report." Accessed June 4, 2011. http://www.eia.gov/cneaf/electricity/epm/epm_sum.html.

UNEP (United Nations Environment Programme). 2007. "Buildings Can Play Key Role In Combating Climate Change". Accessed June 2011. http://www.unep.org/Documents.Multilingual/Default.asp?DocumentID=502\&ArticleID=5545\&l=en

Webber, C. A., J. A. Roberson, M. C. McWhinney, R. E. Brown, M. J. Pinckard, and J. F. Busch. 2006. "After-Hours Power Status of Office Equipment in the USA." Energy 31(14):2823-2838. 
XJ Technologies. 2009. "Anylogic Overview". Accessed June 4, 2011. http://www.xjtek.com/anylogic/overview/.

Yudelson, J. 2010. Greening Existing Buildings. New York, NY: Green Source/McGraw-Hill.

\section{AUTHOR BIOGRAPHIES}

ELIE AZAR is a PhD student in Civil and Environmental Engineering at the University of WisconsinMadison. He received a Bachelor's Degree in Mechanical Engineering from Polytechnique Montreal and a Master's degree in Civil and Environmental Engineering from the University of Wisconsin-Madison. His email address is eazar@wisc.edu.

CAROL C. MENASSA is the M.A. Mortenson Assistant Professor in the Department of Civil and Environmental Engineering at the University of Wisconsin-Madison. She received a Master's of Science in Finance and a $\mathrm{PhD}$ in Civil and Environmental Engineering from the University of Illinois UrbanaChampaign. Her email address is menassa@wisc.edu. 